\title{
QUALIDADE INTERNA E EXTERNA DE OVOS DE POEDEIRAS COMERCIAIS COM CASCAS NORMAL E VÍTREA
}

\section{INTERNAL AND EXTERNAL QUALITY OF COMMERCIAL LAYING HENS EGGS WITH NORMAL AND VITREOUS EGGSHELL}

\author{
Daniela Reis Vilela ${ }^{1}$ \\ Leticia Souza Silva Carvalho ${ }^{1^{*}}$ \\ Naiara Simarro Fagundes ${ }^{1}$ \\ Evandro de Abreu Fernandes ${ }^{1}$ \\ 'Univesidade Federal de Uberlândia, Uberlândia, MG, Brasil. \\ *Autora para correspondência - leticiasouzavet@hotmail.com
}

\section{Resumo}

Objetivou-se com esta pesquisa avaliar a qualidade de ovos de galinhas poedeiras classificados em ovos de casca normal e vítrea, produzidos por galinhas em três idades distintas (30, 50 e 70 semanas). Para cada idade foram amostrados 45 ovos de cada tipo de casca. O peso dos ovos em ambos os tipos de casca aumentou com o avanço da idade da galinha. Maior concentração de cálcio na casca foi encontrada nos ovos de casca normal em relação aos de casca vítrea, o teor de fósforo não foi influenciado pelo tipo de casca. A deposição mineral da casca foi constante. A espessura da casca aumentou independentemente do tipo de casca, ao longo da vida reprodutiva da galinha e diminuiu quando a ave se tornou mais velha. O percentual de albúmen aumentou, enquanto a percentagem de proteína e $\mathrm{pH}$ do albúmen diminuiram ao longo das idades. Percentagem da gema, umidade e $\mathrm{pH}$ diminuíram com o aumento da idade da poedeira, enquanto proteína bruta e extrato etéreo aumentaram. Os ovos de casca vítrea apresentaram casca de qualidade inferior àqueles de casca normal sem, contudo, haver um comprometimento da qualidade interna dos ovos.

Palavras-chave: análises físicas; qualidade do ovo; tipo de cascas.

\begin{abstract}
The objective of this study was to evaluate the internal and external quality of eggs classified as eggs with normal eggshell and eggs with vitreous eggshell, produced by hens at three different ages. Forty-five eggs of each eggshell type, normal and vitreous, were sampled at the ages of 30, 50, and 70 weeks. The weight of the egg, in both types of eggshell, increased with the advancing age of the hen. Higher concentration of calcium was found in eggs with normal eggshells comparing to eggs with vitreous eggshells. The eggshell type did not affect phosphorus percentage. The mineral deposition of the eggshell was constant. The skin thickness increased irrespective of the shell along the reproductive life of the chicken and decreased when the bird became older. The percentage of albumen increased, while the percentage of albumen protein and $\mathrm{pH}$ decreased throughout the ages. Percentage of egg yolk, humidity, and $\mathrm{pH}$ decreased with increase of age of the laying hen, whereas crude protein and lipid increased. Eggs with vitreous eggshell showed eggshell with lower quality compared to those with normal eggshell, without, however, compromising the internal quality of albumen and yolk.
\end{abstract}

Keywords: egg quality; eggshell types; physical analysis.

Enviado em: 09 dezembro de 2012

Aceito em: 01 setembro 2016 


\section{Introdução}

O ovo representa uma importante fonte nutricional, especialmente rico em proteínas de alto valor biológico com nutrientes como os carotenóides luteína, zeaxantina, vitaminas e minerais essenciais à saúde humana ${ }^{(1)}$, além de seu baixo valor de mercado, que o torna acessível à maioria dos consumidores ${ }^{(2)}$.

Comparativamente, a proteína do ovo apresenta um valor nutricional maior do que as proteínas de outras fontes como leite, peixes e feijão. Além disso, o ovo contém quantidades significativas de ácidos graxos insaturados (linoléico e oléico), minerais (ferro, fósforo, magnésio, sódio, potássio, cloro, iodo, manganês enxofre, cobre e zinco), vitaminas (A, D, E, K e do complexo B) e gorduras ${ }^{(3)}$.

A qualidade dos ovos é de suma importância para o desempenho econômico da avicultura de postura. Um fator determinante para a manutenção da qualidade do ovo é a integridade da casca considerada sua "embalagem" natural. A casca deve ser íntegra, sem deformações e trincas que comprometem seu conteúdo interno ${ }^{(4)}$.

Qualquer defeito na casca pode comprometer a utilização do ovo tanto para a produção de pintos de um dia como para alimentação. Apesar do acúmulo de conhecimento nos últimos anos, ainda não há domínio de todas as técnicas relacionadas a mudanças no ambiente, na alimentação ou no manejo, necessárias para que os ovos atinjam os canais de mercado com a qualidade de casca desejada. Fatores como nutrição adequada, problemas sanitários do plantel, práticas de manejo, condições ambientais e genéticas podem influenciar sua qualidade ${ }^{(5)}$.

A casca de ovos pode se apresentar alterada em relação à forma (deformados, com estrangulamento mediano, corrugados ou enrugados e achatados de lado etc.), cor (perda de cor, amarelados, pintas amareladas e manchadas), odor (mofo e contaminação), espessura (mole ou sem casca, casca fina, poroso e porosidade nos extremos), textura (superfície lisa, concreções, deposição de cálcio deficiente) e trincas (fissuras e quebrados) ${ }^{(6)}$. Considerando as alterações que surgem na casca dos ovos de galinhas poedeiras, encontra-se no mercado, entre os ovos de casca normal, uma ocorrência conhecida como casca vítrea, frequentemente encontrada e muitas vezes refugada pelos consumidores por causarem um visual de desqualificação dos ovos.

A casca vítrea caracteriza-se por pontos cinza claro, com diâmetros variados espalhados por toda a superfície do ovo, sugerindo alguma alteração na casca que vai se tornando mais evidente com o aumento no tempo de armazenamento ou de exposição na prateleira dos supermercados e sacolões. Não se conhecem bem os fatores responsáveis pela produção desse tipo de casca, da mesma forma que se desconhece seu verdadeiro impacto sobre a qualidade da casca ou sobre a qualidade interna dos ovos no momento da ovoposição.

Neste sentido, objetivou-se com esta pesquisa comparar variáveis químicas e físicas, comumente usados para definir qualidade externa e interna de ovos de galinhas de postura comercial, entre ovos de casca normal e ovos de casca vítrea.

\section{Material e Métodos}

Os ovos coletados para avaliação foram produzidos por aves de um único lote às 30,50 e 70 semanas de idade.

Foi realizado um delineamento experimental inteiramente casualizado em esquema fatorial $2 \times 3$ (tipo de casca: normal e vítrea $x$ idade: 30, 50, 70 semanas). No dia da amostragem dos ovos foi realizada a coleta diária conforme a rotina da granja. Da primeira coleta de ovos do barracão teste foram aleatoriamente separadas 20 bandejas, perfazendo 600 ovos, que foram reservados dentro da sala de 
classificação de ovos e ali permaneceram armazenados em condições ambientais por 24 horas, de forma a facilitar a classificação dos ovos em casca vítrea e casca normal. Após esse período, os ovos foram repassados um a um e classificados visualmente em ovos de cascas normal ou vítrea, dos quais foram aleatoriamente selecionados 45 ovos de casca normal e 45 ovos de casca vítrea para cada idade, totalizando 90 ovos por idade.

Em seguida os ovos foram transferidos ao Laboratório de Nutrição Animal (LANRA) da Faculdade de Medicina Veterinária da Universidade Federal de Uberlândia, onde foram realizadas as análises físicas e bromatológicas.

Os ovos foram individualmente identificados e pesados em balança eletrônica Marte com escala de precisão de 0,5 grama. A seguir, foram seccionados com tesoura reta de ponta fina no sentido diagonal, e pesados separadamente albúmen, gema e casca, e o percentual de cada componente do ovo foi calculado em relação ao peso do ovo íntegro.

As cascas dos ovos foram lavadas em água corrente e suas membranas foram removidas. Depois, as cascas foram colocadas para secar em estufa à temperatura de $105^{\circ} \mathrm{C}$ durante duas horas. Em seguida, tiveram sua face interna corada com solução de azul de metileno ( 1 grama/100 mL de etanol a $70 \%$ ) para que a cor azul se difundisse através dos poros, facilitando a visualização dos mesmos na face externa das cascas. Na sequência, procedeu-se a contagem visual dos poros em área de $1 \mathrm{~cm}^{2}$, com auxilio de uma lupa com aumento de 3,6 vezes, nos pólos maior, menor e região equatorial, conforme metodologia de Peebles e Brake ${ }^{(7)}$.

A espessura da casca foi medida com auxílio de micrômetro digital (marca Mitutoyo), nos pólos maior, menor e região equatorial, e seu valor foi expresso em milímetros (mm).

Cinco cascas foram agrupadas a fim de formar uma amostra composta, dando um total de nove amostras contendo cinco cascas para os ovos de casca vítrea e normal, para cada uma das idades, para a realização das análises bromatológicas. As cascas foram trituradas em moinho convencional (Elo) e peneiradas em tela de dois milímetros, pesadas e colocadas na Mufla. Em seguida, determinou-se o percentual de matéria mineral, cálcio (método de oxidimetria) e fósforo (método colorimétrico).

Para determinação da qualidade interna dos ovos, o albúmen de cinco ovos foi agrupado a fim de formar uma amostra, perfazendo um total de nove amostras por tratamento (casca normal e vítrea), para cada uma das idades, para realização das análises bromatológicas.

As amostras de albúmen foram homogeneizadas para determinação do $\mathrm{pH}$ com peagâmetro digital da marca Gehaka. Em seguida, foram dispostas na estufa de circulação forçada a $55^{\circ} \mathrm{C}$ por 72 horas para determinação da matéria seca e obtenção da umidade por diferença. A seguir, determinou-se matéria mineral e proteína bruta (método de Kjeldahl).

Da mesma forma, as gemas de cinco ovos foram agrupadas dando um total de nove amostras por tratamento, para cada uma das idades, e a mesma metodologia anteriormente citada foi realizada para determinação do $\mathrm{pH}$, matéria mineral e proteína bruta, além de extrato etéreo que foi determinado por meio do Extrator Soxhlet.

Os resultados obtidos de cada uma das variáveis testadas foram submetidos ao teste de normalidade Shapiro-Wilk e realizada Análise de Variância para os tipos de casca, idade e sua interação. Para os resultados significativos, as médias foram comparadas entre si pelo teste de Tukey a $5 \%$ de significância.

\section{Resultados e Discussão}

Não houve interação do tipo de casca e idade das aves para peso do ovo, percentagem de casca, albúmen e gema (Tabela 1). Para os tipos de casca, normal e vítrea, não houve diferença significativa para peso e percentual dos principais componentes dos ovos. 
Tabela 1. Peso do ovo e percentagem de casca, albúmen e gema de ovos de casca normal e vítrea produzidos por galinhas Dekalb White às 30,50 e 70 semanas de idade

\begin{tabular}{llcccc}
\hline & & $\begin{array}{c}\text { Peso do ovo } \\
\text { (g) }\end{array}$ & Casca (\%) & Albúmen (\%) & Gema (\%) \\
\hline Tipo da & Normal & 62,75 & 13,30 & 55,21 & 28,74 \\
casca & Vitrea & 62,88 & 13,30 & 55,28 & 28,74 \\
\hline \multirow{2}{*}{ Idade } & 30 semanas & $62,08^{\mathrm{b}}$ & $13,18^{\mathrm{b}}$ & $53,73^{\mathrm{c}}$ & $29,77^{\mathrm{a}}$ \\
& 50 semanas & $61,99^{\mathrm{b}}$ & $13,20^{\mathrm{b}}$ & $55,44^{\mathrm{b}}$ & $28,64^{\mathrm{b}}$ \\
& 70 semanas & $64,38^{\mathrm{a}}$ & $13,52^{\mathrm{a}}$ & $55,58^{\mathrm{a}}$ & $27,41^{\mathrm{c}}$ \\
\hline $\mathbf{C V ( \% )}$ & & 7,08 & 7,54 & 4,86 & 8,07 \\
\hline \multirow{2}{*}{ P Valor } & Tipo & 0,8147 & 0,9981 & 0,8265 & 0,3490 \\
& Idade & 0,0003 & 0,0411 & 0,0001 & 0,0001 \\
& Tipo $\mathrm{x}$ Idade & 0,7631 & 0,2100 & 0,4649 & 0,6220 \\
\hline
\end{tabular}

* Médias seguidas de letras diferentes na coluna diferem entre si pelo teste de Tukey a $5 \%$ de significância $(\mathrm{P}<0,05)$.

Com relação às idades, observou-se que o peso dos ovos bem como o percentual de casca foram maiores em ovos produzidos por poedeiras de 70 semanas de idade. Foi possível notar um aumento no percentual de albúmen à medida que a idade das aves aumentou. Comportamento inverso foi apresentado para o percentual de gema que sofreu redução ao longo da idade.

É sabido que o peso do ovo aumenta com a idade da poedeira ${ }^{(8)}$ e que a proporção de seus componentes pode variar em função da idade, fato que pôde ser comprovado no presente trabalho. Os resultados apresentados (Tabela 1) foram semelhantes aos relatos de Silversides ${ }^{(9)}$, que avaliou a influencia da idade da poedeira sobre a qualidade de ovos a 35, 45, 60 e 75 semanas de idade. O autor observou aumento do peso do ovo com aumento da idade. O percentual da gema aumentou até 60 semanas de idade e depois se reduziu, enquanto o percentual de albúmen aumentou ao longo da idade das poedeiras, situação semelhante à observada no presente estudo, em que se observou aumento no percentual de albúmen e redução no percentual de gema; contudo, a redução na proporção da gema foi notada a partir de 50 semanas de idade.

Segundo Rutz et al. ${ }^{(10)}$, do início ao final do ciclo produtivo, o peso do ovo aumenta à medida que a poedeira envelhece, não ocorrendo, no entanto, aumento proporcional da casca. Este fato não foi observado nos resultados expostos no presente trabalho (Tabela 1), em que o aumento significativo do ovo foi acompanhado por aumento percentual da casca. Este fato pode ter ocorrido devido à linhagem utilizada o que, aliado à nutrição adequada à idade da poedeira, proporcionou condições ideais para a manutenção da qualidade da casca.

Para os componentes dos ovos, ovos de casca normal e vítrea apresentaram a mesma proporção. Na qualidade interna dos ovos nenhuma diferença significativa foi observada nas variáveis avaliadas, sendo que ambos os tipos de casca apresentaram o mesmo comportamento com o avanço da idade da poedeira.

Não houve interação do tipo de casca e idade da poedeira para os percentuais de cálcio e fósforo (Tabela 2). Ovos de casca normal apresentaram percentual de cálcio significativamente superior em comparação aos ovos de casca vítrea. Entretanto, o teor de fósforo não foi influenciado pelo tipo de casca. Comparando as diferentes idades, o percentual de cálcio foi menor em ovos de aves jovens (30 semanas) em relação às demais idades, que foram estatisticamente iguais entre si. No entanto, a concentração de fósforo da casca foi maior em 50 semanas de idade em relação aos de 30 e 70 que não diferiram entre si. 
Tabela 2. Composição percentual de matéria mineral (MM), cálcio e fósforo, espessura e poros de casca normal e vítrea de ovos de galinhas Dekalb White às 30, 50 e 70 semanas de idade

\begin{tabular}{|c|c|c|c|c|c|c|}
\hline & & $\begin{array}{c}\text { Cálcio } \\
(\%)\end{array}$ & $\begin{array}{c}\text { Fósforo } \\
(\%)\end{array}$ & $\begin{array}{l}\text { MM } \\
(\%)\end{array}$ & $\begin{array}{c}\text { Espessura } \\
(\mathbf{m m})\end{array}$ & $\begin{array}{c}\text { Poros } \\
\left(\mathbf{n}^{\circ} / \mathrm{cm}^{2}\right)\end{array}$ \\
\hline \multirow{2}{*}{$\begin{array}{l}\text { Tipo de } \\
\text { casca }\end{array}$} & Normal & $45,06^{a}$ & 0,50 & 95,30 & 0,336 & 121,03 \\
\hline & Vitrea & $44,47^{b}$ & 0,48 & 94,69 & 0,334 & 112,80 \\
\hline \multirow{3}{*}{ Idade } & 30 semanas & $44,54^{b}$ & $0,48^{b}$ & 94,70 & 0,334 & 102,39 \\
\hline & 50 semanas & $45,04^{a}$ & $0,50^{\mathrm{a}}$ & 94,97 & 0,359 & 116,95 \\
\hline & 70 semanas & $44,73^{a}$ & $0,49^{b}$ & 95,30 & 0,311 & 131,41 \\
\hline \multirow[t]{2}{*}{$\mathrm{CV}(\%)$} & & 0,75 & 2,96 & 0,39 & 3,14 & 3,51 \\
\hline & Tipo & $<, 0001$ & $<, 0001$ & $<, 0001$ & 0,1109 & $<, 0001$ \\
\hline \multirow[t]{2}{*}{$P$ valor } & Idade & 0,0003 & 0,0008 & $<, 0001$ & $<, 0001$ & $<, 0001$ \\
\hline & Tipo x Idade & 0,1060 & 0,0783 & $<, 0001$ & $<, 0001$ & $<, 0001$ \\
\hline
\end{tabular}

Interações significativas foram observadas para o tipo de casca e idade das aves para percentual de matéria mineral, espessura de casca e número de poros (Tabela 3). Para o tipo de casca normal, não houve diferença no percentual de matéria mineral nas diferentes idades das poedeiras. Este achado permite concluir que, com o aumento da idade e, consequentemente, o aumento do ovo, a deposição mineral da casca foi mantida constante. Acredita-se que este fato seja devido à suplementação de cálcio na ração de acordo com as necessidades das aves em cada idade, outro fator determinante foi a capacidade das aves em depositar esse cálcio na casca, sendo ela jovem ou velha.

Fatores como linhagem da poedeira, idade, estado sanitário do plantel, manejo, nutrição e fatores ambientais são capazes de influenciar a qualidade dos ovos $^{(11)}$; no entanto, Washburn ${ }^{(12)}$ destacou a nutrição como um fator determinante da qualidade, além de atuar no peso e espessura ${ }^{(13)} \mathrm{e}$ porosidade da $\operatorname{casca}^{(14)}$. Neste sentido, a nutrição adequada à idade das aves pode ter contribuído para a manutenção do percentual de casca e matéria mineral ao longo da pesquisa, bem como percentual de cálcio.

Todavia, para a casca vítrea, a matéria aumentou gradativamente com o avanço da idade da poedeira, sendo seu maior valor observado em galinhas de 70 semanas de idade. Dentro das idades, ovos de casca vítrea apresentaram menor teor de matéria mineral, em comparação com ovos normais, a 30 e 50 semanas de idade, equiparando aos níveis de cascas normais quando as aves que os produziram tinham 70 semanas de idade.

Tanto ovos de casca normal quanto ovos de casca vítrea apresentaram o mesmo comportamento para espessura de casca (Tabela 3). Ambos os tipos de casca sofreram aumento na espessura da casca para aves de 50 semanas de idade e posterior redução quando as aves apresentavam 70 semanas de idade. Akyurek \& Okur ${ }^{(15)}$ encontraram resultados semelhantes quando avaliaram a espessura da casca em galinhas com 22 e 50 semanas. Resultados distintos foram relatados por Gheisari et al. ${ }^{(16)}$, que verificaram menor espessura de casca em aves de 49 a 50 semanas de idade.

De acordo com Roland ${ }^{(17)}$ e Hamilton ${ }^{(18)}$, o tamanho do ovo aumenta mais rapidamente com a idade da poedeira do que o peso da casca, fazendo com que a espessura diminua. A menor espessura de casca em aves velhas se relaciona com uma menor atividade enzimática da anidrase carbônica associada ou não à menor absorção intestinal de cálcio, mobilização óssea e menor taxa de retenção deste mineral.

Dentro da mesma idade, poedeiras com 30 semanas de idade produziram ovos de casca vítrea mais espessos que os de casca normal; no entanto, nas demais idades, os ovos de casca normal foram 
mais espessos (Tabela 3). Comparando-se os ovos de casca normal com aqueles de casca vítrea, ficou demonstrado que, a partir de 50 semanas de idade, os ovos de casca vítrea apresentaram cascas significativamente mais finas, fato que pode indicar maior fragilidade deste tipo de casca.

Em relação ao número de poros, ovos de casca normal e vítrea apresentaram o mesmo comportamento com o aumento da idade das poedeiras. As cascas apresentaram gradativamente maior número de poros por $\mathrm{cm}^{2}$ à medida que a idade das aves avançou, o que corrobora a afirmação de Rosa et al. ${ }^{(19)}$ de que poedeiras mais velhas produzem ovos mais porosos. Todavia, dentro da mesma idade, ovos de casca vítrea apresentaram menor número de poros em relação aos ovos de casca normal.

Tabela 3. Desdobramento da interação do tipo de casca e idade das galinhas Dekalb White para percentual de matéria mineral da casca de ovos, espessura de casca ( $\mathrm{mm})$ e número de poros $\left(\mathrm{cm}^{2}\right)$

\begin{tabular}{|c|c|c|c|c|c|}
\hline \multicolumn{6}{|c|}{ Matéria Mineral } \\
\hline \multirow[b]{2}{*}{ Tipo de casca } & \multicolumn{3}{|c|}{ Idade } & \multirow[b]{2}{*}{$\mathrm{CV}(\%)$} & \multirow[b]{2}{*}{$P$ valor } \\
\hline & 30 semanas & 50 semanas & 70 semanas & & \\
\hline Normal & $95,32^{2 \mathrm{~A}}$ & $95,30^{\mathrm{Aa}}$ & $95,28^{2 A}$ & & \\
\hline Vítrea & $94,10^{\text {bC }}$ & $94,65^{\mathrm{Bb}}$ & $95,32^{2 A}$ & 0,39 & $<, 0001$ \\
\hline \multicolumn{6}{|c|}{ Espessura de Casca } \\
\hline Normal & $0,329^{\mathrm{bB}}$ & $0,363^{\text {aA }}$ & $0,316^{2 C}$ & & \\
\hline Vítrea & $0,339^{\mathrm{aB}}$ & $0,355^{\mathrm{bA}}$ & $0,308^{b C}$ & 3,14 & $<, 0001$ \\
\hline \multicolumn{6}{|c|}{ Número de Poros } \\
\hline Normal & $105,6^{2 C}$ & $118,5^{\mathrm{aB}}$ & $139,0^{2 \mathrm{~A}}$ & & \\
\hline Vítrea & $99,2^{\mathrm{bC}}$ & $115,5^{\mathrm{bB}}$ & $123,9^{\mathrm{bA}}$ & 3,52 & $<, 0001$ \\
\hline
\end{tabular}

*Médias seguidas de letras minúsculas (maiúsculas) diferentes na coluna (linha), diferem entre si pelo teste de Tukey a $5 \%$ de significância $(\mathrm{P}<0,05)$.

É sabido que, à medida que a poedeira envelhece, a qualidade externa dos ovos produzidos por ela diminui $^{(8,1120)}$, o que foi confirmado no presente trabalho, uma vez que os valores de espessura de casca e o número de poros evidenciaram a diminuição na qualidade da casca dos ovos com o aumento da idade da poedeira.

Deficiência de manganês(21), infecção por Mycoplasma synoviae-assoziierte ${ }^{(22)}$, falha na secagem rápida da casca, alta umidade são algumas das teorias encontradas na literatura sobre a ocorrência de ovos de casca vítrea; entretanto, pouco se sabe sobre a influencia da casca vítrea sobre a qualidade interna e externa dos ovos e de que forma ela poderia impactar na mineralização da casca.

$\mathrm{Na}$ análise bromatológica do albúmen (Tabela 4) não houve diferenças entre ovos de casca normal e vítrea, para percentual de umidade, proteína bruta e $\mathrm{pH}$. O percentual de umidade do albúmen aumentou à medida que a poedeira ganhou idade, enquanto a proteína bruta diminuiu. Uma justificativa para 0 aumento da umidade e redução da proteína é que, apesar de não ter havido diminuição percentual da casca ao longo do período avaliado, o número de poros aumentou facilitando as trocas gasosas com o ambiente, já que os ovos do presente trabalho permaneceram armazenados à temperatura ambiente por 24 horas. $\mathrm{O}$ aumento das trocas gasosas favorece a hidrólise de cadeias de aminoácidos por enzimas presentes no albúmen, destruindo a estrutura protéica e liberando a água ligada a grandes moléculas protéicas ${ }^{(23)}$.

Os valores de $\mathrm{pH}$ do albúmen sofreram redução significativa quando as poedeiras alcançaram 50 semanas, mantendo-se estáveis a 70 semanas de idade. Silversides e $\operatorname{Scott}^{(20)}$ também observaram redução no $\mathrm{pH}$ desse componente dos ovos; contudo, a redução de $\mathrm{pH}$ foi observada para albúmen de aves de 59 semanas de idade. 
Tabela 4. Níveis de umidade, proteína bruta $(\mathrm{PB})$ e $\mathrm{pH}$ do albúmen de ovos de galinhas Dekalb White às 30,50 e 70 semanas de idade, Uberlândia-MG, 2012

\begin{tabular}{llccc}
\hline & & Umidade (\%) & PB (\%) & pH \\
\hline \multirow{2}{*}{$\begin{array}{l}\text { Tipo de } \\
\text { casca }\end{array}$} & Normal & 88,32 & 9,82 & 8,51 \\
\cline { 2 - 5 } Idade & Vitrea & 88,16 & 9,73 & 8,49 \\
\cline { 2 - 5 } & 30 semanas & $87,55^{\mathrm{c}}$ & $10,15^{\mathrm{a}}$ & $8,65^{\mathrm{a}}$ \\
\cline { 2 - 5 } & 50 semanas & $88,42^{\mathrm{b}}$ & $9,55^{\mathrm{b}}$ & $8,45^{\mathrm{b}}$ \\
\cline { 2 - 5 } CV(\%) & 70 semanas & $88,75^{\mathrm{a}}$ & $9,62^{\mathrm{b}}$ & $8,38^{\mathrm{b}}$ \\
\hline \multirow{2}{*}{ P valor } & 0,41 & 2,24 & 2,03 \\
& Tipo & 0,1159 & 0,1259 & 0,7136 \\
\cline { 2 - 5 } & Idade & $<, 0001$ & $<, 0001$ & $<, 0001$ \\
\cline { 2 - 5 } & Tipo $x$ Idade & 0,1659 & 0,3473 & 0,0878 \\
\hline
\end{tabular}

* Médias seguidas de letras diferentes na coluna diferem entre si pelo teste de Tukey a $5 \%$ de significância $(\mathrm{P}<0,05)$.

Tabela 5. Niveis de umidade, proteína bruta $(\mathrm{PB})$, extrato etéreo $(\mathrm{EE})$ e $\mathrm{pH}$ da gema de ovos de galinhas Dekalb White às 30,50 e 70 semanas de idade

\begin{tabular}{llcccc}
\hline & & $\begin{array}{c}\text { Umidade } \\
(\%)\end{array}$ & $\begin{array}{c}\text { PB } \\
\text { (\%) }\end{array}$ & Ph & $\begin{array}{c}\text { EE } \\
\text { (\%) }\end{array}$ \\
\hline \multirow{2}{*}{$\begin{array}{l}\text { Tipo de } \\
\text { casca }\end{array}$} & Normal & $51,77^{\mathrm{a}}$ & 17,67 & 6,01 & 29,96 \\
\cline { 2 - 6 } Idade & Vitrea & $50,89^{\mathrm{b}}$ & 17,12 & 6,01 & 29,85 \\
\cline { 2 - 6 } & 30 semanas & $54,98^{\mathrm{a}}$ & 15,95 & $6,21^{\mathrm{a}}$ & $29,28^{\mathrm{b}}$ \\
\cline { 2 - 6 } & 50 semanas & $49,50^{\mathrm{b}}$ & 17,87 & $5,82^{\mathrm{c}}$ & $30,18^{\mathrm{a}}$ \\
\hline CV(\%) & 70 semanas & $49,51^{\mathrm{b}}$ & 18,36 & $6,02^{\mathrm{b}}$ & $30,25^{\mathrm{a}}$ \\
\hline P valor & Tipo & 1,66 & 2,62 & 1,76 & 1,85 \\
\cline { 2 - 6 } & Idade & 0,0004 & $<, 0001$ & 0,9673 & 0,4758 \\
\cline { 2 - 6 } & Tipo $x$ Idade & 0,0001 & $<, 0001$ & $<, 0001$ & $<, 0001$ \\
\hline
\end{tabular}

* Médias seguidas de letras diferentes na coluna diferem entre si pelo teste de Tukey a $5 \%$ de significância $(\mathrm{P}<0,05)$.

Para gema, ovos de casca vítrea apresentaram menor teor de umidade que os ovos de casca normal (Tabela 5). O percentual de umidade da gema reduziu com o envelhecimento da poedeira, bem como aumentou o teor de extrato etéreo, resultados semelhantes aos de Sartori et al. ${ }^{(24)}$, que também observaram o mesmo comportamento para essas variáveis ao longo da vida produtiva da poedeira. Ahn et al. ${ }^{(23)}$ relataram aumento no conteúdo de sólidos da gema e, portanto, redução no percentual de água. $\mathrm{O} \mathrm{pH}$ da gema seguiu o mesmo comportamento observado para o $\mathrm{pH}$ de albúmen, ou seja, o pH sofreu redução ao longo período avaliado.

Houve interação entre idade da poedeira e tipo de casca para percentual de proteína bruta da gema (Tabela 6). Ovos de casca normal apresentaram aumento no teor protéico da gema para poedeiras de 70 semanas de idade. Aumento no teor protéico da gema também foram relatados por Sartori et al. ${ }^{(24)}$ em função da idade da poedeira; no entanto, os autores observaram aumento de proteína em gema de ovos de poedeiras a partir de 40 semanas de idade.

Para casca vítrea, o aumento de proteína ocorreu quando as poedeiras tinham 50 semanas de idade e se manteve até 70 semanas. No entanto, dentro da mesma idade, o teor protéico foi maior em gema de 
ovos de casca normal para poedeiras de 30 semanas de idade, situação inversa aconteceu quando as aves apresentaram 50 semanas. Todavia a 70 semanas de idade, poedeiras produziram ovos com teor de proteína bruta estatisticamente igual para ambos os tipos de casca.

Tabela 6. Desdobramento de interação entre tipo de casca e idade de ovos com casca normal e vítrea de galinhas Dekalb White para proteína bruta da gema de ovos

\begin{tabular}{|c|c|c|c|c|c|}
\hline \multirow{2}{*}{$\begin{array}{c}\text { Tipo } \\
\text { (Casca) }\end{array}$} & \multicolumn{3}{|c|}{ Idade } & \multirow{2}{*}{ CV (\%) } & \multirow{2}{*}{$P$ valor } \\
\hline & 30 semanas & 50 semanas & 70 semanas & & \\
\hline Normal & $17,14^{2 \mathrm{~B}}$ & $17,51^{\mathrm{bB}}$ & $18,37^{\mathrm{Aa}}$ & 2,62 & $<, 0001$ \\
\hline Vitrea & $14,78^{\mathrm{bB}}$ & $18,24^{2 A}$ & $18,37^{\mathrm{aA}}$ & & \\
\hline
\end{tabular}

*Médias seguidas de letras minúsculas (maiúsculas) diferentes na coluna (linha), diferem entre si pelo teste de Tukey a $5 \%$ de significância $(\mathrm{P}<0,05)$.

Poucos trabalhos avaliam a composição bromatológica dos principais componentes dos ovos em função da idade das poedeiras. No entanto, o que parece ser consenso é que, com o aumento da idade da poedeira, ocorre aumento no peso dos ovos e perda da qualidade dos mesmos ${ }^{(25)}$. Apesar de ter havido aumento no peso dos ovos e diminuição da qualidade da casca com o aumento da idade das aves, houve um esforço da poedeira em aumentar a concentração de nutrientes do ovo, uma vez que houve manutenção do percentual de casca com o aumento do tamanho dos ovos, aumento no percentual de proteína bruta e extrato etéreo da gema com o avanço da idade da poedeira.

Ovos de casca normal e vítrea não apresentaram diferenças em relação à qualidade interna. Entretanto, o menor percentual de cálcio e matéria mineral dos ovos de poedeiras observadas com 30 e 50 semanas de idade, aliado à menor espessura de casca de ovos de galinhas de 50 e 70 semanas de idade, sugerem que os ovos de casca vítrea apresentam maior fragilidade de casca, o que poderia concorrer para ocorrências de quebras e trincas, além de maior facilidade de contaminação e perda de qualidade interna ao longo das várias etapas da cadeia produtiva.

Outras investigações a respeito do tema devem ser realizadas a fim de se esclarecerem os fatores envolvidos na produção deste tipo de casca, bem como seus efeitos sobre a qualidade de ovos armazenados ou expostos no varejo para comercialização.

\section{Conclusão}

Os ovos de casca vítrea apresentaram casca de qualidade inferior àqueles de casca normal sem, contudo, haver um comprometimento da qualidade interna dos ovos.

\section{Referências}

1 Aguiar MS, Zaffari S, Hübscher GH. O ovo e sua contribuição na saúde humana. Revista Saúde e Ambiente / Health and Environment Journal. 2009; 10(1)47-55.

2 Rodrigues KRM, Salay E. Atitudes de granjeiros, atacadistas, varejistas e consumidores em relação à qualidade sanitária do ovo de galinha in natura. Revista de Nutrição. 2001; 14(3):185-93. Disponível em: http://www.scielo.br/pdf/rn/v14n3/7784.pdf

3 Sarcinelli MF, Venturini KS, Silva LC. Características dos ovos. Universidade Federal do Espírito Santo - UFES; Pró-reitoria de Extensão - Programa Institucional de Extensão. Boletim Técnico - PIE-UFES: 00707Editado: 20/08/2007. Disponível em: <http://www.agais.com/telomc/b00707_caracteristicas_ovos.pdf > 
4 Hunton P. Research on eggshell structure and quality: An historical overview. Revista Brasileira de Ciência Avícola. 2005; 7(2): 67-71.

5 Vieira DVG, Barreto SLT, Valeriano MH, Jesus LFD, Silva LFF, Mencalha R, Barbosa KS, Mendes RKV, Cassuce MR, Melo TS. Exigências de cálcio e de fósforo disponível para codornas japonesas de 26 a 38 semanas de idade. 2012; 13(1):204-13. Disponível em: $<$ http://www.scielo.br/pdf/rbspa/v13n1/a18v31n1.pdf $>$

6 Deeming, D.C. Large eggs: an incubation challenge. Poultry International. 1996; 35(14):50-54.

7 Peebles ED, Brake J. Relationship of eggshell to stage of embryonic development in broiler breeders. Poultry Science. 1985; 64(12):2388-91.

8 Carvalho FB, Stringhini JH, Jardim Filho RM, Leandro NSM, Café MB, Borges de Deus HAS. Qualidade interna e da casca para ovos de poedeiras comerciais de diferentes linhagens e idades. Ciência Animal Brasileira. 2007; 8(1):25-29.

9 Silversides FG, Villeneuve PI. Is the Haugh unit correction for eggs weight valid for eggs stored at room temperature? Poultry Science. 1994;73(1):50-55.

10 Rutz F, Anciuti MA, Xavier EG, Roll VFB, Rossi P. Avanços na fisiologia e desempenho reprodutivo de aves domésticas. Revista Brasileira de Reprodução Animal. 2007;31(3):307-17. Disponível em: < http://www. cbra.org.br/pages/publicacoes/rbra/download/307.pdf>

11 Ramos KCBT, Camargo AM, De Oliveira ECD, Cedro TMM, Morenz, MJF. Avaliação da idade da poedeira, da temperatura de armazenamento e do tipo de embalagem sobre a qualidade de ovos comerciais. Revista de Ciências Vida Seropédica. 2010; 30(2):37-46. Disponível em: http://www.editora.ufrrj.br/rcv2/vida_30_2/3746\%2007V44\%20avaliacao\%20da\%20idade\%20da.pdf

12 Washburn KW. Incidence, cause and prevention of egg shell breakage in commercial production. Poultry Science. 1982; 61(10):2005-12.

13 Morgan CL. Relationship between breaking strength and the percentage of egg shell. Poultry Science. 1932; 11(3):172-175.

14 Ar A, Paganelli ICV, Reeves RB, Greene DG, Rahn H. The avian egg: water vapor conductance, shell thickness, and functional pore area. The Condor. 1974; 76(2):153-8. Disponível em: $<$ http://elibrary.unm.edu/ sora/Condor/files/issues/v076n02/p0153-p0158.pdf>

15 Akyurek H, Okur AA. Effect of storage time, temperature and hen age on egg quality in free-range layer hens. Journal of Animal and Veterinary Advances. 2009; 8: 1953-8. Disponível em: $<$ http://www.medwelljournals. $\underline{\mathrm{com} / \text { fulltext/?doi=javaa.2009.1953.1958> }}$

16 Gheisari MM, Toghyani M, Samie A; Sanei A, Gheisari AA. Effect of Diets Supplemented with Different Levels of Manganese, Zinc, and Copper from their Organic or Inorganic Sources on Egg Production and Quality Characteristics in Laying Hens. Biological Trace Element Research. 2011; 142(3):557-571.

17 Roland DA. Recent developments in egg shell quality. Feedstuffs. 1976; 48(29):31.

18 Hamilton RGM. Observation on the changes in the physical characteristics the influence egg shell quality in the strains of. White leghorn. Poultry Science. 1978; 57(5):1192-98.

19 Rosa PS, Guidoni AL, Lima IL, Bersch FXR. Influência da temperatura de incubação em ovos de matrizes de corte com diferentes idades e classificados por peso sobre os resultados de incubação. Revista Brasileira de Zootecnia. 2002; 31(2):1011-16. Disponível em: $<$ http://www.scielo.br/pdf/rbz/v31n2s0/21291.pdff $>$

20 Silversides FG, Scott TA. Effect of storage and layer age on quality of eggs from two lines of hens. Poultry 
Science. 2001; 80(8):1240-45.

21 Leach RMJr, Gross JR. The effect of manganese deficiency upon the ultrastructure of the eggshell. Poultry Science. 1983; 62(3):499-504.

22 Morrow C. Bioproperties. Egg Apical Abnormality. Tech Bulletin. 2012; 2. 5p. Disponível em: < http:// www.bioproperties.com.au/!Pages/Publications/Documents/DOC-Bulletin-2012-02.pdfs

23 Ahn DU, Kim SM, Shu H. Effect of egg size and strain and age of hens on the solids content of chicken eggs. Poultry Science. 1997; 76:914-19.

24 Sartori EV, Canniatti-Brazaca SG, Da Cruz SH, Gaziola SA. Concentração de proteínas em gemas de ovos de poedeiras (Gallus Gallus) nos diferentes ciclos de postura e sua interferência na disponibilidade de ferro. Ciência e Tecnologia de Alimentos. 2009; 39(3):481-7. Disponível em: <http://www.scielo.br/scielo. php?script=sci_arttext\&pid $=$ S0101-20612009000300004>

25 Almeida JG, Dahlke F, Maiorka A; Faria Filho DE, Oelke CA. Efeito da idade da matriz no tempo de eclosão, tempo de permanência do neonato no nascedouro e o peso do pintainho. Archives of Veterinary Science. 2006; 11(1):45-9. 